\title{
Minerals with metal-organic framework structures
}

2016 (c) The Authors, some rights reserved; exclusive licensee American Association for the Advancement of Science. Distributed under a Creative Commons Attribution NonCommercial License 4.0 (CC BY-NC). $10.1126 /$ sciadv. 1600621

\author{
Igor Huskić, ${ }^{1}$ Igor V. Pekov, ${ }^{2}$ Sergey V. Krivovichev, ${ }^{3 *}$ Tomislav Friščić $^{1 *}$
}

Metal-organic frameworks (MOFs) are an increasingly important family of advanced materials based on open, nanometer-scale metal-organic architectures, whose design and synthesis are based on the directed assembly of carefully designed subunits. We now demonstrate an unexpected link between mineralogy and MOF chemistry by discovering that the rare organic minerals stepanovite and zhemchuzhnikovite exhibit structures found in well-established magnetic and proton-conducting metal oxalate MOFs. Structures of stepanovite and zhemchuzhnikovite, exhibiting almost nanometer-wide and guest-filled apertures and channels, respectively, change the perspective of MOFs as exclusively artificial materials and represent, so far, unique examples of open framework architectures in organic minerals.

\section{INTRODUCTION}

Metal-organic frameworks (MOFs) are a rapidly developing family of advanced materials, with applications in hydrogen storage, carbon sequestration, catalysis, gas separation, photovoltaics, and more (1-4), synthesized from inorganic and organic components judiciously selected to form two- or three-dimensional architectures with open or potential voids (5-7). Here, we demonstrate the appearance of MOF structures in nature as rare oxalate minerals stepanovite and zhemchuzhnikovite $(8,9)$ that are based on open anionic frameworks analogous to those found in magnetic (10) or proton-conductive (11) metal oxalate MOFs. Metal oxalates are the largest family of organic minerals (12), mainly generated by biogeochemical processes such as mineral weathering and in vivo formation by living organisms $(13,14)$. Their structures are dominated by mononuclear complexes and one-dimensional coordination polymers of hydrated metal ions $\left[\mathrm{Mg}^{2+}\right.$ in glushinskite (15), $\mathrm{Cu}^{2+}$ in moolooite (16), $\mathrm{Mn}^{2+}$ in lindbergite (17), and $\mathrm{Fe}^{2+}$ in humboldtine (18)] bridged by oxalate anions $\left(\mathbf{o x}^{2-}\right)$. However, there are several oxalate minerals of more complex compositions that have not yet been structurally characterized, notably stepanovite (Strunz class 10.AB.20, reported in 1942) and zhemchuzhnikovite (Strunz class 10.AB.35, reported in 1963), first discovered near the estuary of Lena River (Sakha-Yakutia, Siberia, Russia) and accepted by the International Mineralogical Association in $1964(8,9,12)$. Both minerals appear as thin veinlets, which consist of green transparent grained or fibrous aggregates with, very rarely, isometric crystals $\sim 0.05 \mathrm{~mm}$ across (Fig. 1A and fig. S1), in lignite. They are associated with other natural salts of organic acids, for example, oxalates (whewellite, weddellite, and glushinskite) and unspecified acetates, and with calcite and dolomite. The rarity of stepanovite and zhemchuzhnikovite in nature is definitely caused by very uncommon geochemical environment and physical conditions of their formation: at both coal deposits Tyllakh and Chai-Tumus, these water-soluble minerals were found in drill cores at depths up to $230 \mathrm{~m}$ below the day surface, in the permafrost zone, within lignite saturated by natural acetic acid (8). The formulae of stepanovite $\left[\mathrm{NaMgFe}(\mathbf{o x})_{3} \cdot 8-9 \mathrm{H}_{2} \mathrm{O}\right]$

'Department of Chemistry, McGill University, 801 Sherbrooke Street West, Montreal, H3A OB8 Quebec, Canada. ${ }^{2}$ Faculty of Geology, Lomonosov Moscow State University, Vorobievy Gory, 119991 Moscow, Russia. ${ }^{3}$ Department of Crystallography, Saint Petersburg State University, University Emb. 7/9, 199034 Saint Petersburg, Russia.

*Corresponding author. Email: tomislav.friscic@mcgill.ca (T.F.); s.krivovichev@spbu.ru (S.V.K.) and zhemchuzhnikovite $\left[\mathrm{NaMg}\left(\mathrm{Fe}_{0.4} \mathrm{Al}_{0.6}\right)(\mathbf{o x})_{3} \cdot 8-9 \mathrm{H}_{2} \mathrm{O}\right]$ were reported by Knipovich et al. (8), along with crystallographic parameters (Table 1) that were determined from powder X-ray diffraction (PXRD) data. We noted that the mineral compositions of stepanovite and zhemchuzhnikovite closely resemble those of anionic oxalate MOFs first developed in the 1990s as magnetic materials (10). These MOFs consist of open $\left[\mathrm{M}^{\mathrm{I}} \mathrm{M}^{\mathrm{III}}(\mathbf{o x})_{3}\right]^{2-}$ frameworks of three-dimensional (3D) $(10,3)$ net or two-dimensional (2D) $(6,3)$ net topology [honeycomb (hcb) topology; Fig. 1B], with monovalent $\left(\mathrm{M}^{\mathrm{I}}\right.$; for example, $\mathrm{Li}^{+}$or $\left.\mathrm{Na}^{+}\right)$ and trivalent cations $\left(\mathrm{M}^{\mathrm{III}}\right.$; for example, $\mathrm{Cr}^{3+}$ or $\left.\mathrm{Fe}^{3+}\right)$ as nodes, and are templated by divalent cations retained in framework cavities. More recently, analogous metal-oxalate structures based on zinc $(19,20)$ or other transition metals (21) have garnered additional interest as ferromagnetic and/or proton-conducting materials (Fig. 1C) $(11,21)$.

The unexpected chemical similarity to known MOFs led us to speculate whether stepanovite and zhemchuzhnikovite might be based on similar open frameworks, prompting structural characterization. Searching the Cambridge Structural Database (CSD) for structures with crystallographic parameters (Table 1) resembling those for stepanovite gave no meaningful results. However, a search for zhemchuzhnikovite parameters (Table 1) revealed isostructurality to $\mathrm{NaMgAl}(\mathbf{o x})_{3} \cdot 9 \mathrm{H}_{2} \mathrm{O}$ [Cambridge Crystallographic Data Centre (CCDC) code YODWUK] (22), a 2D MOF consisting of hcb $\left[\mathrm{NaAl}(\mathbf{o x})_{3}\right]^{2-}$ open framework layers, with $\mathrm{Mg}\left(\mathrm{H}_{2} \mathrm{O}\right)_{6}{ }^{2+}$ guests in layer cavities. Isostructurality and chemical similarity to $\mathrm{NaMgAl}(\mathbf{o x})_{3} \cdot 9 \mathrm{H}_{2} \mathrm{O}$ reinforced our view that zhemchuzhnikovite exhibits an MOF structure.

\section{RESULTS}

For this study, we used samples of minerals collected by the Russian mineralogist P. I. Glushinsky in 1942, later studied by Knipovich et al. (8). Because natural samples appear together with other minerals, we also pursued the preparation of synthetic stepanovite and zhemchuzhnikovite to obtain phase-pure materials and single crystals of improved quality. Synthetic stepanovite was obtained by reacting $\mathrm{Fe}_{2} \mathrm{O}_{3}$ and $\mathrm{MgO}$ with aqueous $\mathrm{NaOH}$ and oxalic acid (23). After 2 days, the solution yielded green crystals of trigonal habit, consistent with that of stepanovite (Fig. 1D and fig. S2) $(8,9,12)$. Synthetic zhemchuzhnikovite was made 
A

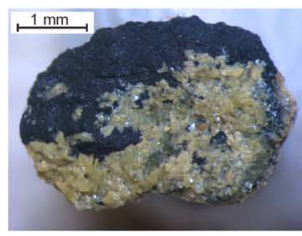

D

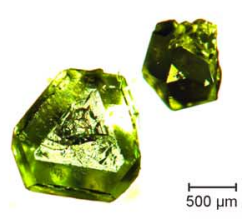

B

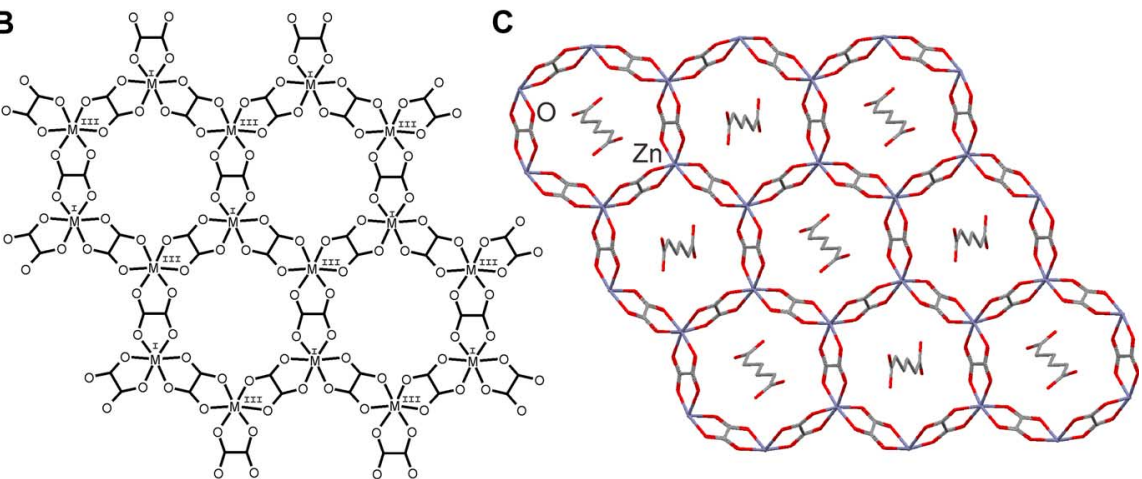

E

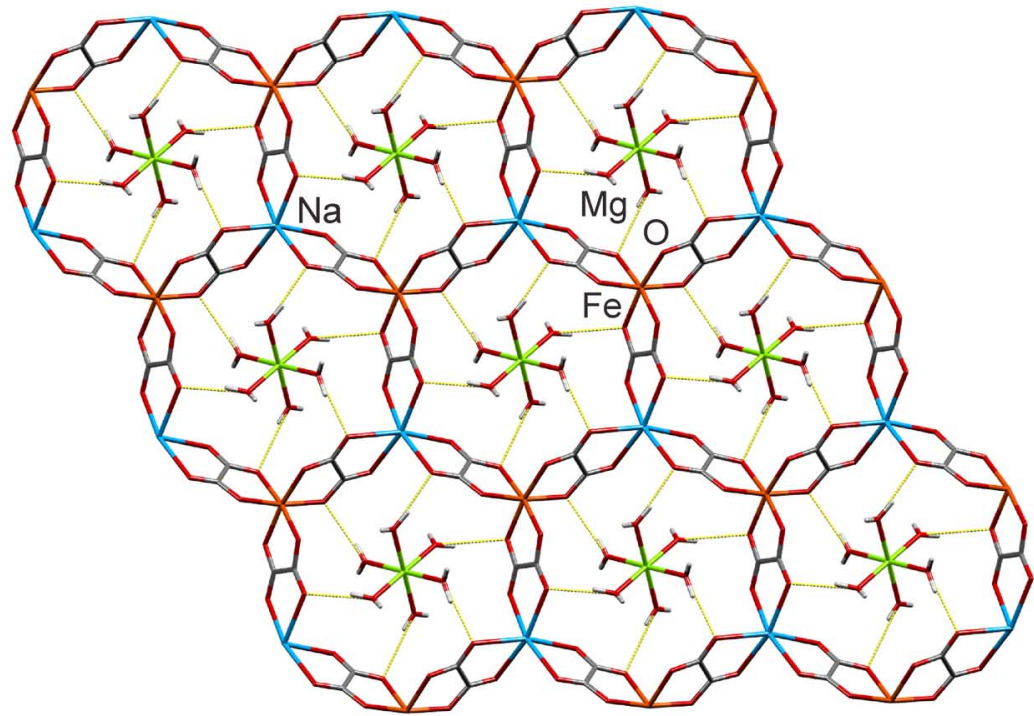

Fig. 1. Stepanovite is a mineral with an MOF structure. (A) Stepanovite sample, Chai-Tumus coal deposit (Sakha-Yakutia, Siberia, Russia; sample from E. I. Nefedov's collection). (B) schematic of an open anionic hcb framework composed of $\mathrm{M}^{\prime}$ and $\mathrm{M}^{\prime \prime \prime}$ nodes bridged by oxalates. (C) A single layer of an analogous zinc-based proton-conducting MOF material, including guests (11). (D) Crystals of synthetic stepanovite. (E) A single metal-organic layer in stepanovite, viewed along the crystallographic $\mathrm{c}$ axis, displaying the anionic hcb $\left[\mathrm{NaFe}(\mathbf{o x})_{3}\right]^{2-}$ framework, with apertures occupied by $\mathrm{Mg}\left(\mathrm{H}_{2} \mathrm{O}\right)_{6}{ }^{2+}$. Hydrogen bonds between $\mathrm{Mg}\left(\mathrm{H}_{2} \mathrm{O}\right)_{6}^{2+}$ guests and $\left[\mathrm{NaFe}(\mathbf{o x})_{3}\right]^{2-}$ framework are highlighted as yellow dotted lines.

by reacting premade $\mathrm{Na}_{3} \mathrm{Fe}(\mathbf{o x})_{3} \cdot 3 \mathrm{H}_{2} \mathrm{O}$, aluminum sulfate, and $\mathrm{MgO}$ with oxalic acid in water, using a 6:4 stoichiometric ratio of $\mathrm{Al}$ and $\mathrm{Fe}$, respectively. The reaction yielded pale yellow-green crystals, with morphology consistent with that of zhemchuzhnikovite (fig. S3).

Single-crystal X-ray diffraction (XRD) structures of synthetic and natural stepanovite and zhemchuzhnikovite confirmed the unit-cell parameters reported by Knipovich et al. (8) (Table 1) and gave unambiguous evidence that these minerals exhibit structures previously found in 2D oxalate MOFs. The stepanovite structure consists of anionic hcb $\left[\mathrm{NaFe}(\mathbf{o x})_{3}\right]^{2-}$ layers, each layer exhibiting apertures of $\sim 0.9 \mathrm{~nm}$ in diameter, occupied with $\mathrm{Mg}\left(\mathrm{H}_{2} \mathrm{O}\right)_{6}{ }^{2+}$ guests hydrogen-bonded to oxalate ions of the pore wall (O...O distances, 2.82 to $2.96 \AA$; O-H... angles, $148^{\circ}$ to $167^{\circ}$ ) (Fig. 1E). In each layer, $\mathrm{Fe}^{3+}$ and $\mathrm{Na}^{+}$adopt octahedral environments of opposite chirality $(\Lambda$ or $\Delta)$.

Layers are separated by water molecules, each forming four hydrogen bonds: two as donors toward oxalates of neighboring layers $(\mathrm{O} \cdots \mathrm{O}$ distances, 2.74 to $2.77 \AA$; O-H... $\mathrm{O}$ angles, $168^{\circ}$ to $175^{\circ}$ ) and two as hydrogen bond acceptors from $\mathrm{Mg}\left(\mathrm{H}_{2} \mathrm{O}\right)_{6}{ }^{2+}$ sitting in neighboring layers (O...O distances, 2.76 to $2.79 \AA$ А; O-H...O angles, $165^{\circ}$ to $176^{\circ}$ ). Hydro- gen bonds around each water molecule form a tetrahedron elongated in crystallographic $c$ direction (Fig. 2A).

Crystal structure determination and refinement of natural and synthetic zhemchuzhnikovite revealed open hcb topology layers with $\mathrm{Al}^{3+}$ and $\mathrm{Fe}^{3+}$ disordered over the same site (Fig. 3A). Depending on crystal choice, occupational parameters of $\mathrm{Fe}^{3+}$ and $\mathrm{Al}^{3+}$ in synthetic crystals varied between 0.41:0.59 and 0.76:0.24, whereas a single crystal from the natural sample gave 0.69:0.31. For each investigated crystal, the $\mathrm{Fe}^{3+} / \mathrm{Al}^{3+}$ disorder appeared statistical, without no indication of ordering into a supercell. We conclude that the structure of zhemchuzhnikovite, $\mathrm{NaMg}\left(\mathrm{Fe}_{1-x} \mathrm{Al}_{x}\right)(\mathbf{o x})_{3} \cdot 9 \mathrm{H}_{2} \mathrm{O}$, can accommodate diverse $\mathrm{Al} / \mathrm{Fe}$ compositions, also evidenced by atomic emission analysis of single crystals from different batches of synthetic zhemchuzhnikovite, with $x$ in the range of 0.21 to 0.86 . The structure of $\mathrm{NaMg}\left(\mathrm{Fe}_{0.41} \mathrm{Al}_{0.59}\right)$ $(\mathbf{o x})_{3} \cdot 9 \mathrm{H}_{2} \mathrm{O}$ was anisotropically refined to $R_{1}<0.04$ in space group $P 3 \mathrm{cl}$, identical to $\mathrm{NaMgAl}(\mathbf{o x})_{3} \cdot 9 \mathrm{H}_{2} \mathrm{O}$ (22). Attempted refinement in centrosymmetric group $P \overline{3} c 1$ gave a poorer result, that is, $R_{1}>0.08$. As in stepanovite, cavities of each layer are occupied by $\mathrm{Mg}\left(\mathrm{H}_{2} \mathrm{O}\right)_{6}{ }^{2+}$ hydrogenbonded to oxalates lining the pore [O...O distances, 2.83 to $2.99 \AA$; 
Table 1. Crystallographic data for stepanovite and zhemchuzhnikovite. Comparison of crystallographic and general parameters reported by Knipovich et al. (8) to the investigated natural and synthetic samples in this study.

\begin{tabular}{|c|c|c|c|}
\hline \multicolumn{4}{|c|}{ Stepanovite } \\
\hline & Reported by Knipovich et al. (8) & Natural & Synthetic \\
\hline Crystal system & Trigonal & Trigonal & Trigonal \\
\hline Formula & $\mathrm{NaMgFe}\left(\mathrm{C}_{2} \mathrm{O}_{4}\right)_{3} \cdot 8-9 \mathrm{H}_{2} \mathrm{O}$ & $\mathrm{NaMgFe}\left(\mathrm{C}_{2} \mathrm{O}_{4}\right)_{3} \cdot 9 \mathrm{H}_{2} \mathrm{O}$ & $\mathrm{NaMgFe}\left(\mathrm{C}_{2} \mathrm{O}_{4}\right)_{3} \cdot 9 \mathrm{H}_{2} \mathrm{O}$ \\
\hline Space group & Not reported & $R 3 c$ & $R 3 c$ \\
\hline$a(\AA)$ & $9.78^{*}$ & $9.8367(13)^{*}$ & $9.887(13)^{*}$ \\
\hline$c(\AA)$ & 36.67 & $36.902(5)$ & $37.03(5)$ \\
\hline$a / c$ ratio & $1: 3.73-1: 3.76^{*}$ & $1: 3.75^{*}$ & $1: 3.75^{*}$ \\
\hline$V\left(\AA^{3}\right)$ & 3070 & $3092.2(7)$ & $3135(9)$ \\
\hline$Z$ & 6 & 6 & 6 \\
\hline Color & Green & Greenish yellow & Green \\
\hline Density $\left(\mathrm{g} \mathrm{cm}^{-3}\right)$ & 1.69 & 1.71 (calculated) & 1.68 (calculated) \\
\hline \multicolumn{4}{|c|}{ Zhemchuzhnikovite } \\
\hline & Reported by Knipovich et al. (8) & Natural & Synthetic \\
\hline Crystal system & Trigonal & Trigonal & Trigonal \\
\hline Formula & $\mathrm{NaMg}\left(\mathrm{Fe}_{0.4} \mathrm{Al}_{0.6}\right)\left(\mathrm{C}_{2} \mathrm{O}_{4}\right)_{3} \cdot 8-9 \mathrm{H}_{2} \mathrm{O}$ & $\mathrm{NaMg}\left(\mathrm{Fe}_{0.31} \mathrm{Al}_{0.69}\right)\left(\mathrm{C}_{2} \mathrm{O}_{4}\right)_{3} \cdot 9 \mathrm{H}_{2} \mathrm{O}$ & $\mathrm{NaMg}\left(\mathrm{Fe}_{1-x} \mathrm{Al}_{x}\right)\left(\mathrm{C}_{2} \mathrm{O}_{4}\right)_{3} \cdot 9 \mathrm{H}_{2} \mathrm{O}^{\dagger}$ \\
\hline Space group & Not reported & $P 3 c 1^{\ddagger}$ & $P 3 C 1^{\ddagger}$ \\
\hline$a(\AA)$ & 16.67 & $16.809(7)$ & $16.919(2)^{\S}$ \\
\hline$c(\AA)$ & 12.51 & $12.658(6)$ & $12.561(2)^{\S}$ \\
\hline$a / c$ ratio & 1:0.75-1:0.739 & $1: 0.753$ & $1: 0.742^{\S}$ \\
\hline$V\left(\AA^{3}\right)$ & 3001 & $3097(2)$ & $3113.8(9)^{\S}$ \\
\hline$Z$ & 6 & 6 & 6 \\
\hline Color & Green & Greenish yellow & Yellow-green \\
\hline Density & $1.62-1.66$ & 1.64 (calculated) & 1.63 (calculated) \\
\hline
\end{tabular}

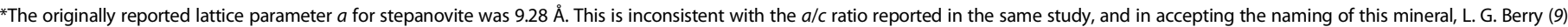

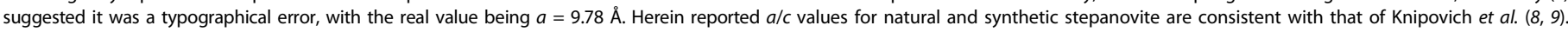

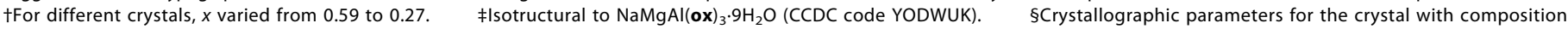
$\mathrm{NaMg}\left(\mathrm{Fe}_{0.41} \mathrm{Al}_{0.59}\right)\left(\mathrm{C}_{2} \mathrm{O}_{4}\right)_{3} \cdot 9 \mathrm{H}_{2} \mathrm{O}$.

$\mathrm{O}-\mathrm{H} \cdots \mathrm{O}$ angles, $161^{\circ}$ to $177^{\circ}$ for $\left.\mathrm{NaMg}\left(\mathrm{Fe}_{0.41} \mathrm{Al}_{0.59}\right)(\mathbf{o x})_{3} \cdot 9 \mathrm{H}_{2} \mathrm{O}\right]$, and the layers are interconnected by hydrogen bonding to interstitial water.

In each hcb layer of zhemchuzhnikovite, all $\mathrm{Fe}^{3+}$ ions adopt the same chirality, opposite to that of $\mathrm{Na}^{+}$in the same layer. However, unlike stepanovite, layers in zhemchuzhnikovite form ABABAB stacks with all hcb apertures aligned to form channels of $\sim 0.9-\mathrm{nm}$ diameter. The difference between stepanovite and zhemchuzhnikovite structures is evident in experimental and simulated PXRD patterns of zhemchuzhnikovite, which are noticeably different from those of stepanovite (Fig. 2C). The PXRD patterns of natural and synthetic zhemchuzhnikovite showed excellent fit to that which was calculated on the basis of the herein determined structure (table S2). The hydrogen bonding arrangement around interstitial water molecules in zhemchuzhnikovite resembles stepanovite: Each water molecule is a twofold donor toward oxalate ions in neighboring layers (O...O distances, 2.72 to $2.80 \AA$; $\mathrm{O}-\mathrm{H}$... $\mathrm{O}$ angles, $150^{\circ}$ to $176^{\circ}$ ) and a twofold acceptor toward guest $\mathrm{Mg}\left(\mathrm{H}_{2} \mathrm{O}\right)_{6}{ }^{2+}$ in neighboring layers [O...O distances, 2.74 to $2.75 \AA$;
$\mathrm{O}-\mathrm{H} \cdots \mathrm{O}$ angles, $158^{\circ}$ to $175^{\circ}$ for $\left.\mathrm{NaMg}\left(\mathrm{Fe}_{0.41} \mathrm{Al}_{0.59}\right)(\mathbf{o x})_{3} \cdot 9 \mathrm{H}_{2} \mathrm{O}\right]$. Composition of synthetic zhemchuzhnikovite was confirmed by thermogravimetric analysis (TGA) (fig. S5).

The structural similarity of stepanovite and zhemchuzhnikovite to the proton-conducting oxalate MOFs is marked $(11,21)$. Proton conductivity in these MOFs results largely from a Grotthuss-type proton-hopping mechanism, enabled by a $2 \mathrm{D}$ network of hydrogen bonds involving water molecules in the interlayer space and protic species located either between the MOF layers or lodged in the pores $(11,24)$. On the basis of these considerations, stepanovite exhibits potential for proton conduction, because there is an uninterrupted $2 \mathrm{D}$ net of short hydrogen bonds in the interlayer space, involving interstitial water molecules and $\mathrm{Mg}\left(\mathrm{H}_{2} \mathrm{O}\right)_{6}{ }^{2+}$ cations. Hydrogen bonding in both mineral structures extends beyond interlayer space, in the crystallographic $z$ direction, giving a 3D network for stepanovite (Fig. 4A) and one-dimensional columns extending through MOF channels (Fig. 4B) for zhemchuzhnikovite. 

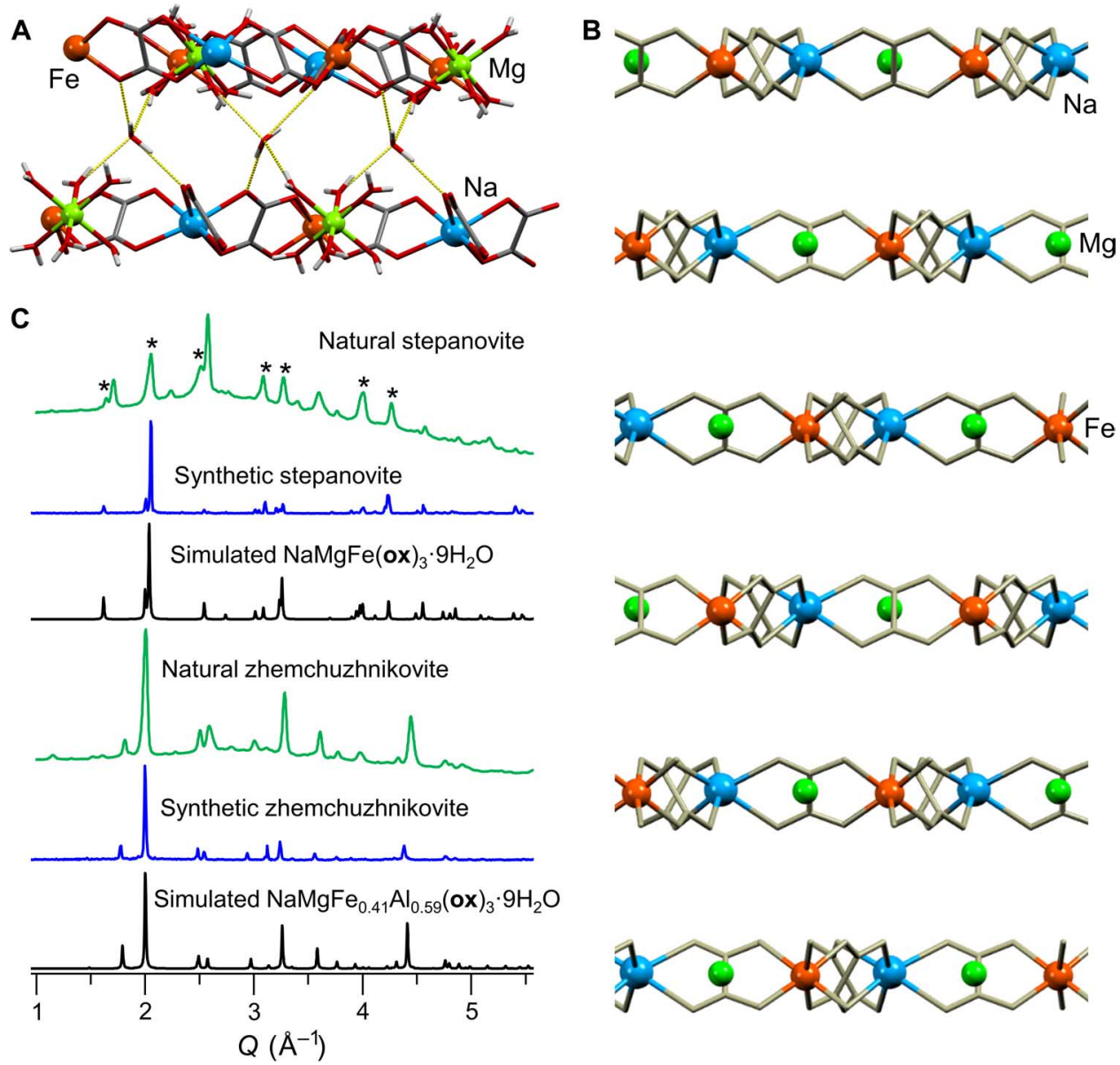

Fig. 2. Structure of stepanovite and PXRD patterns of MOF minerals. (A) Hydrogen bonding environment of water guests between hcb layers of stepanovite. (B) Stepanovite structure viewed parallel to crystallographic $a$ axis (water molecules were omitted for clarity), with offset ABCABC arrangement evident from stacking of $\mathrm{Na}^{+}, \mathrm{Mg}^{2+}$, and $\mathrm{Fe}^{3+}$ ions (blue, green, and orange, respectively) in neighboring layers. (C) Comparison of PXRD patterns (top to bottom): natural stepanovite, synthetic stepanovite, simulated $\mathrm{NaMgFe}(\mathbf{o x})_{3} \cdot 9 \mathrm{H}_{2} \mathrm{O}$, natural zhemchuzhnikovite, synthetic zhemchuzhnikovite, and simulated $\mathrm{NaMgFe}_{0.41} \mathrm{Al}_{0.59}(\mathbf{o x})_{3} \cdot 9 \mathrm{H}_{2} \mathrm{O}$. The PXRD pattern of natural stepanovite is affected by the presence of a number of other minerals, of which the most abundant one is glushinskite, as well as amorphous organic material. For clarity, principal reflections of stepanovite are designated with "*." List of indexed x-ray reflections for natural stepanovite and zhemchuzhnikovite is given in tables S1 and S2.

Thermal stability of zhemchuzhnikovite and stepanovite is consistent with the properties of proton-conducting oxalate MOFs reported by Sadakiyo et al. (11), with mild heating $\left(90^{\circ} \mathrm{C}\right)$ leading to partial dehydration, which is reversed upon exposure to saturated water vapor at room temperature. TGA after thermal dehydration reveals that stepanovite loses 3 equiv of water upon heating, consistent with removal of water between the hcb layers. For zhemchuzhnikovite, heating leads to the loss of crystallinity and removal of 6 equiv of water, indicating the loss of at least $50 \%$ of coordinated water guests in MOF channels. Upon exposure to saturated water vapor at room temperature, both stepanovite and zhemchuzhnikovite regain the original structure and water content (figs. S6 to S10). The removal and absorption of water can be repeated at least three times (Fig. 4C and fig. S6) for both minerals, each time regenerating the initial MOF. The fact that stepanovite loses only interstitial water upon thermal treatment is indicative of water mobility and consistent with a lack of communication between the pores of MOF layers. For zhemchuzh- nikovite, the more extensive loss of water, including that coordinated to $\mathrm{Mg}^{2+}$ ions in pores, can be explained by the existence of channels formed by stacking of MOF layers.

The difference in crystal structures of stepanovite and zhemchuzhnikovite points to the possibility of modifying the stacking of hcb sheets by forming a solid solution of multiple metal ions (25). Because differences between the structures of zhemchuzhnikovite and stepanovite also lead to different hydrogen-bonded motifs involving guest water molecules, this control over the stacking of MOF sheets would be of potential interest in proton-conducting materials (11). To evaluate how the $\mathrm{Al} / \mathrm{Fe}$ ratio influences the formation of zhemchuzhnikovite structure, we used mechanochemical liquid-assisted grinding (LAG) (26) to synthesize solid solutions from premade $\mathrm{NaMgAl}(\mathbf{o x})_{3} \cdot 9 \mathrm{H}_{2} \mathrm{O}$ and $\mathrm{NaMgFe}(\mathbf{o x})_{3} \cdot 9 \mathrm{H}_{2} \mathrm{O}$ (stepanovite). LAG was shown to be an efficient method of preparing solid solutions of coordination polymers $(27,28)$. PXRD analysis of samples prepared by milling $\operatorname{NaMgAl}(\mathbf{o x})_{3} \cdot 9 \mathrm{H}_{2} \mathrm{O}$ and $\mathrm{NaMgFe}(\mathbf{o x})_{3} \cdot 9 \mathrm{H}_{2} \mathrm{O}$ in different stoichiometric ratios for $30 \mathrm{~min}$, 

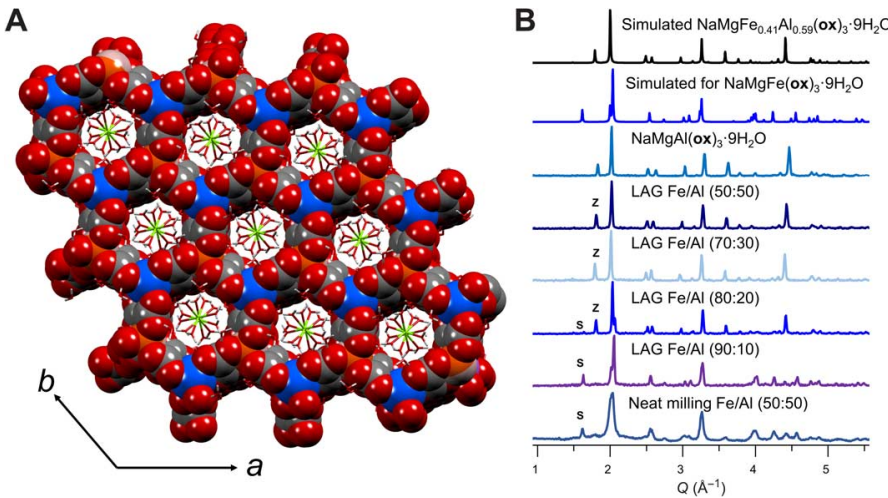

Fig. 3. Crystal structure of zhemchuzhnikovite and role of aluminum in its formation. (A) Zhemchuzhnikovite structure viewed down the crystallographic $c$ axis, demonstrating the alignment of MOF layers into channels occupied by $\mathrm{Mg}\left(\mathrm{H}_{2} \mathrm{O}\right)_{6}{ }^{2+}$. For clarity, the hcb layers are shown in spacefilling mode, $\mathrm{Mg}\left(\mathrm{H}_{2} \mathrm{O}\right)_{6}{ }^{2+}$, and interstitial water molecules using capped sticks. (B) PXRD patterns (top to bottom): simulated $\mathrm{NaMgFe}_{0.41} \mathrm{Al}_{0.59}(\mathbf{o x})_{3} \cdot 9 \mathrm{H}_{2} \mathrm{O}$, simulated $\mathrm{NaMgFe}(\mathbf{o x})_{3} \cdot 9 \mathrm{H}_{2} \mathrm{O}, \mathrm{NaMgAl}(\mathbf{o x})_{3} \cdot 9 \mathrm{H}_{2} \mathrm{O}$, products of LAG of $\mathrm{NaMgFe}(\mathbf{o x})_{3} \cdot 9 \mathrm{H}_{2} \mathrm{O}$ and $\mathrm{NaMgAl}(\mathbf{o x})_{3} \cdot 9 \mathrm{H}_{2} \mathrm{O}$ in different stoichiometric ratios $\left(50: 50,70: 30,80: 20\right.$, and 90:10), and product of dry milling of $\mathrm{NaMgFe}(\mathbf{o x})_{3} \cdot 9 \mathrm{H}_{2} \mathrm{O}$ and $\mathrm{NaMgAl}(\mathbf{o x})_{3} \cdot \mathrm{9H}_{2} \mathrm{O}$ in 50:50 ratio. The PXRD patterns reveal formation of zhemchuzhnikovite structure for Fe/Al ratios up to $\sim 80: 20$, whereas a higher $\mathrm{Fe} / \mathrm{Al}$ ratio favors stepanovite structure. Two characteristic reflections that distinguish zhemchuzhnikovite and stepanovite structures are highlighted by " $\mathrm{z}$ " and "s," respectively.

using a small amount of water as a grinding liquid ( $20 \mu \mathrm{l}$ per $200 \mathrm{mg}$ solid mixture), reveals the zhemchuzhnikovite structure forming with $\mathrm{Fe} / \mathrm{Al}$ ratios up to $0.8: 0.2$ (Fig. $3 \mathrm{~B}$ ). At higher ratios, the stepanovite structure becomes preferred. LAG of synthetic stepanovite on its own did not lead to a change in PXRD pattern, indicating that the appearance of the zhemchuzhnikovite structure is tentatively related to $\mathrm{NaMgAl}(\mathbf{o x})_{3} \cdot 9 \mathrm{H}_{2} \mathrm{O}$, because of the formation of $\mathrm{NaMg}\left(\mathrm{Fe}_{1-x} \mathrm{Al}_{x}\right)$ $(\mathbf{o x})_{3} \cdot 9 \mathrm{H}_{2} \mathrm{O}$ solid solutions. Fourier transform infrared attenuated total reflectance (ATR) spectra of LAG products exhibit absorption bands resembling $\mathrm{NaMgAl}(\mathbf{o x})_{3} \cdot 9 \mathrm{H}_{2} \mathrm{O}$ and $\mathrm{NaMgFe}(\mathbf{o x})_{3} \cdot 9 \mathrm{H}_{2} \mathrm{O}$ (fig. S11). Dry milling of a $1: 1$ stoichiometric mixture of $\mathrm{NaMgFe}(\mathbf{o x})_{3} \cdot 9 \mathrm{H}_{2} \mathrm{O}$ and $\mathrm{NaMgAl}(\mathbf{o x})_{3} \cdot 9 \mathrm{H}_{2} \mathrm{O}$ for 30 min results largely in the broadening of $\mathrm{x}$-ray reflections, with stepanovite and zhemchuzhnikovite phases still discernable in the PXRD pattern (Fig. 3B). However, adding water to the dry-milled mixture $(20 \mu \mathrm{l}$ per $200 \mathrm{mg})$ and milling for five more minutes again produced the zhemchuzhnikovite structure, consistent with LAG.

\section{DISCUSSION}

Establishing that open MOF structures can form in a natural environment demonstrates that coordination-driven self-assembly used in creating advanced materials in the laboratory can also play a role in geological processes. Whereas channels and voids are well known for inorganic minerals $(29,30)$, zhemchuzhnikovite and stepanovite are so far the only examples of organic minerals exhibiting open structures. The structure of zhemchuzhnikovite, with $\sim 0.9-\mathrm{nm}$ channels, is particularly remarkable among organic minerals. Although neither zhemchuzhnikovite nor stepanovite can exhibit permanent porosity, because of the presence of

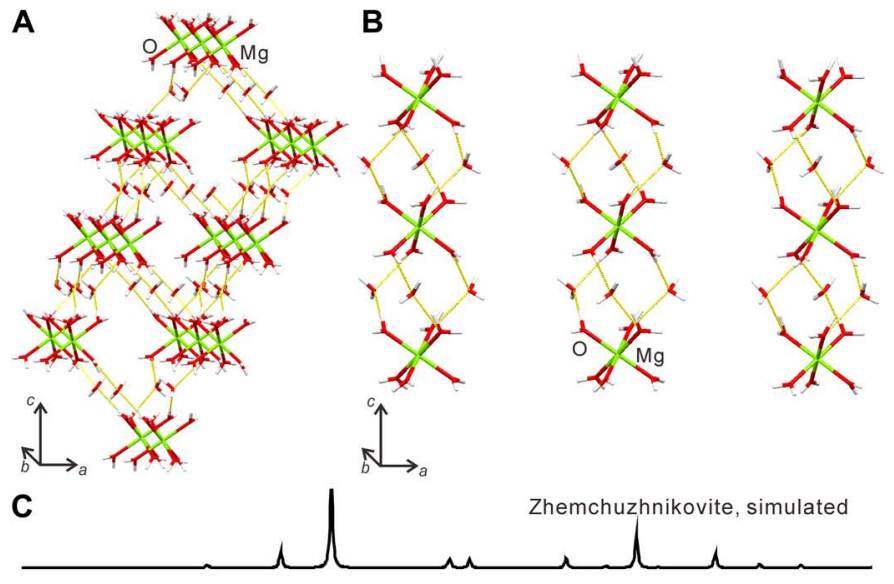

Zhemchuzhnikovite, first dehydration at $90^{\circ} \mathrm{C}$

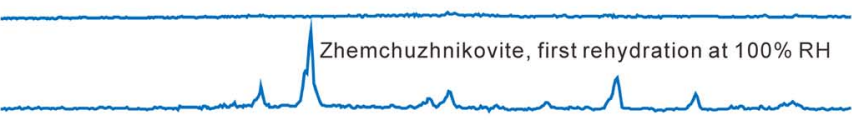

Zhemchuzhnikovite, second dehydration at $90^{\circ} \mathrm{C}$

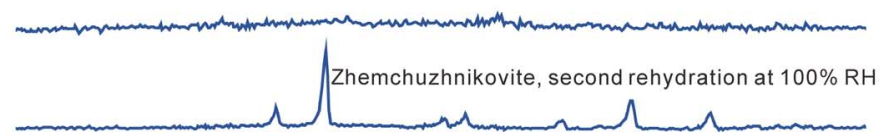

Zhemchuzhnikovite, third dehydration at $90^{\circ} \mathrm{C}$

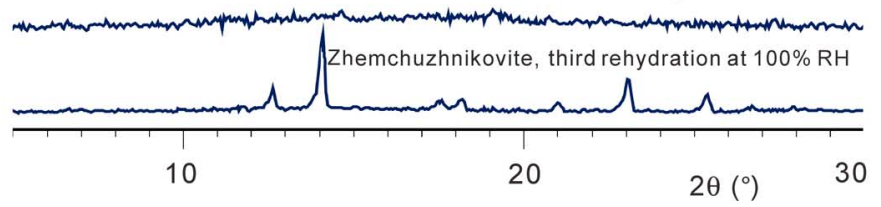

Fig. 4. Hydrogen-bonded motifs in stepanovite and zhemchuzhnikovite and reversibility of thermal dehydration of zhemchuzhnikovite. (A) The 3D hydrogen-bonded network of $\mathrm{Mg}\left(\mathrm{H}_{2} \mathrm{O}\right)_{6}{ }^{2+}$ ions and interlayer water molecules in stepanovite. (B) Three parallel hydrogenbonded columns of $\mathrm{Mg}\left(\mathrm{H}_{2} \mathrm{O}\right)_{6}{ }^{2+}$ ions and interlayer water molecules in zhemchuzhnikovite, each propagating through a channel formed by the overlap of hcb layers. For clarity, the metal-organic hcb layers are omitted. (C) The reversibility of structural changes upon dehydration and rehydration of synthetic zhemchuzhnikovite is demonstrated by comparison of PXRD patterns (top to bottom): simulated zhemchuzhnikovite $\mathrm{NaMgFe}_{0.41} \mathrm{Al}_{0.59}(\mathbf{o x})_{3} \cdot 9 \mathrm{H}_{2} \mathrm{O}$; simulated for stepanovite $\mathrm{NaMgFe}(\mathbf{o x})_{3} \cdot 9 \mathrm{H}_{2} \mathrm{O}$; and zhemchuzhnikovite after one, two, and three cycles of thermal dehydration at $90^{\circ} \mathrm{C}$ and rehydration by exposure to $100 \%$ relative humidity (RH) at room temperature.

$\mathrm{Mg}\left(\mathrm{H}_{2} \mathrm{O}\right)_{6}{ }^{2+}$ guests in the MOF pores, they exhibit similarities to previously reported analogous MOFs $(10,11,19-21)$. In particular, both minerals can undergo reversible loss and sorption of water guests, demonstrating the stability of individual hcb layers upon desolvation, and exhibit extended hydrogen-bonded architectures that suggest the potential for proton conduction (24). The open metal-organic architectures in zhemchuzhnikovite and stepanovite change our view of MOFs as strictly artificial materials and hint to the possibility that the future may unravel other MOF minerals, potentially even microporous ones. These expectations are not far-fetched, bearing in mind that some organic minerals involve multifunctional molecules already used in MOF synthesis, such as mellitic acid or different purines $(12,31-34)$. 


\section{MATERIALS AND METHODS}

\section{Solution synthesis}

$\mathrm{NaMgAl}(\mathbf{o x})_{3} \cdot 9 \mathrm{H}_{2} \mathrm{O}$ was prepared according to a published procedure (22). Synthetic stepanovite was prepared by dissolving stoichiometric amounts of $\mathrm{NaOH}, \mathrm{MgO}$ ( $\geq 99 \%$ trace metals basis, 325 -mesh powder; Sigma-Aldrich), and $\mathrm{Fe}_{2} \mathrm{O}_{3}$ (nanopowder; Sigma-Aldrich) in aqueous oxalic acid solution. The resulting green solution was stirred overnight, filtered, and left to evaporate at $4^{\circ} \mathrm{C}$. Green, rhombohedral crystals were obtained after 2 days. Synthetic zhemchuzhnikovite was obtained by the evaporation of an aqueous solution obtained by mixing saturated aqueous $\mathrm{Na}_{3} \mathrm{Fe}(\mathbf{o x})_{3} \cdot 3 \mathrm{H}_{2} \mathrm{O}$, aluminum sulfate, and $\mathrm{MgO}$ with aqueous oxalic acid, using a $6: 4 \mathrm{Al} / \mathrm{Fe}$ stoichiometric ratio. After 2 days at $4^{\circ} \mathrm{C}$, yellow-green needles formed.

\section{Single-crystal XRD}

Crystal structures of synthetic and natural stepanovite and zhemchuzhnikovite were determined by single-crystal XRD. Diffraction measurements were made on Bruker D8 APEX2 and Bruker APEX DUO $\mathrm{x}$-ray diffractometers, using graphite-monochromated $\mathrm{MoK}_{\alpha}$ radiation $(\lambda=0.71073 \AA)$. Data were collected in $\omega$ scan mode $(2 \theta \leq$ $\left.54^{\circ}\right)$. Structures were solved by direct methods in SHELXS and refined using SHELXL (35) on $F^{2}$ using all data. Hydrogen atoms were located using the electron difference map when permitted by data quality. Calculations were performed and images were prepared using WinGX program suite (36). Structures have been deposited to the CSD, with deposition codes 1408093 to 1408095 for synthetic samples and 1431678 and 1431679 for natural samples.

\section{Mechanochemical milling}

Mechanochemical milling was performed for $30 \mathrm{~min}$, using an MM200 Retsch mill operating at $25 \mathrm{~Hz}$, in custom-made Teflon jars (14-ml volume), and with two stainless steel balls (each ball was $8 \mathrm{~mm}$ in diameter and $1.9 \mathrm{~g}$ in weight).

\section{Powder x-ray diffraction}

Powder $\mathrm{x}$-ray diffraction data for synthetic samples were collected on Bruker D2 LYNXEYE Phaser using nickel-filtered $\mathrm{Cu} K_{\alpha}$ radiation $(\lambda=1.54056 \AA)$, and those for natural samples were collected using a Rigaku R-AXIS Rapid II diffractometer (curved image plate, $d=127.4 \mathrm{~mm}$; Debye-Scherrer geometry; $\operatorname{Co} K_{\alpha}, \lambda=$ $1.79021 \AA$ ).

\section{Cambridge Structural Database}

CSD searches were performed using CSD version 5.36 (November 2014) +1 update.

\section{Fourier transform infrared ATR}

Fourier transform infrared ATR was measured using Bruker VERTEX 70 with PLATINUM diamond ATR unit.

\section{Thermogravimetric analysis}

Thermogravimetric analysis was performed using a Mettler-Toledo TGA DSC 1 Star thermobalance (using alumina crucibles) and TA Instruments Q500 (using platinum pans) in a stream of air (flow rate, $60 \mathrm{ml} \mathrm{min}^{-1}$; heating rate, $10^{\circ} \mathrm{C} \mathrm{min}^{-1}$; sample size, 5 to $10 \mathrm{mg}$ ). Data were processed using Mettler STARe 9.01 Software.

\section{SUPPLEMENTARY MATERIALS}

Supplementary material for this article is available at http://advances.sciencemag.org/cgi/ content/full/2/8/e1600621/DC1

fig. S1. Scanning electron microscopy image of aggregates of isometric zhemchuzhnikovite crystals from Chai-Tumus coal deposit, Sakha-Yakutia, Russia (sample from E. I. Nefedov's collections).

fig. S2. Morphologies for stepanovite, reported by Knipovich et al. (8).

fig. S3. Morphologies for zhemchuzhnikovite.

fig. S4. TGA of bulk synthetic stepanovite.

fig. S5. TGA of bulk synthetic zhemchuzhnikovite.

fig. S6. Comparison of PXRD patterns for synthetic stepanovite after one, two, and three cycles of dehydration at $90^{\circ} \mathrm{C}$ and rehydration at $100 \% \mathrm{RH}$.

fig. S7. Thermal analysis of zhemchuzhnikovite after thermal dehydration at $90^{\circ} \mathrm{C}$ for 16 hours: TGA (top) and DSC (bottom).

fig. S8. Thermal analysis of zhemchuzhnikovite after thermal dehydration at $90^{\circ} \mathrm{C}$, followed by exposure to $100 \%$ RH: TGA (top) and DSC (bottom).

fig. S9. Thermal analysis of stepanovite after thermal dehydration at $90^{\circ} \mathrm{C}$ : TGA (top) and DSC (bottom). fig. S10. Thermal analysis of stepanovite after thermal dehydration at $90^{\circ} \mathrm{C}$, followed by exposure to $100 \%$ RH: TGA (top) and DSC (bottom).

fig. S11. Overlay of FTIR-ATR spectra for mechanochemically prepared zhemchuzhnikovite analogs with different Al:Fe ratios.

table S1. PXRD data of bulk stepanovite from Chai-Tumus coal deposit, Siberia, Russia, were indexed on the basis of herein determined crystal structure.

table S2. PXRD data of bulk zhemchuzhnikovite from Chai-Tumus coal deposit, Siberia, Russia, were indexed on the basis of herein determined crystal structure.

data file S1. Crystallographic data for crystal structures of natural and synthetic samples of stepanovite and zhemchuzhnikovite.

data file S2. checkCIF for crystal structures of natural and synthetic samples of stepanovite and zhemchuzhnikovite.

\section{REFERENCES AND NOTES}

1. H. Furukawa, K. E. Cordova, M. O'Keeffe, O. M. Yaghi, The chemistry and applications of metal-organic frameworks. Science 341, 1230444 (2013).

2. B. F. Hoskins, R. Robson, Design and construction of a new class of scaffolding-like materials comprising infinite polymeric frameworks of 3D-linked molecular rods. A reappraisal of the zinc cyanide and cadium cyanide structures and the synthesis and structure of the diamond-related frameworks [N(CH3)4][CuIZnII(CN)4] and Cul[4,4',4",4"'-tetracyanotetraphenylmethane]BF4.xC6H5NO2. J. Am. Chem. Soc. 112, 1546-1554 (1990).

3. O. M. Yaghi, G. Li, H. Li, Selective binding and removal of guests in a microporous metalorganic framework. Nature 378, 703-706 (1995).

4. M. Fujita, Y. J. Kwon, S. Washizu, K. Ogura, Preparation, clathration ability, and catalysis of a two-dimensional square network material of cadmium(II) and 4,4'-bipyridine. J. Am. Chem. Soc. 116, 1151-1152 (1994).

5. S. R. Batten, N. R. Champness, X.-M. Chen, J. Garcia-Martinez, S. Kitagawa, L. Öhrström, M. O'Keeffe, M. Paik Suh, J. Reedijk, Terminology of metal-organic frameworks and coordination polymers (IUPAC Recommendations 2013). Pure Appl. Chem. 85, 1715-1724 (2013).

6. S. R. Batten, N. R. Champness, X.-M. Chen, J. Garcia-Martinez, S. Kitagawa, L. Öhrström, M. O'Keeffe, M. Paik Suh, J. Reedijk, Coordination polymers, metal-organic frameworks and the need for terminology guidelines. CrystEngComm 14, 3001-3004 (2012).

7. A. G. Slater, A. I. Cooper, Function-led design of new porous materials. Science $\mathbf{3 4 8}$ aaa8075 (2015).

8. Y. N. Knipovich, A. I. Komkov, E. I. Nefedov, On stepanovite and the new mineral zhemchuzhnikovite. Trudy Vses. Nauchno-Issled. Geol. Inst. 96, 131-135 (1963).

9. M. Fleischer, New mineral names. Am. Mineral. 49, 439-448 (1964).

10. S. Descurtins, H. W. Schmalle, P. Schneuwly, J. Ensling, P. A. Guetlich, A concept for the synthesis of 3-dimensional homo- and bimetallic oxalate-bridged networks $\left[\mathrm{M}_{2}(\mathrm{ox})_{3}\right]_{n}$. Structural, Moessbauer, and magnetic studies in the field of molecular-based magnets. J. Am. Chem. Soc. 116, 9521-9528 (1994).

11. M. Sadakiyo, T. Yamada, K. Honda, H. Matsui, H. Kitagawa, Control of crystalline protonconducting pathways by water-induced transformations of hydrogen-bonding networks in a metal-organic framework. J. Am. Chem. Soc. 136, 7701-7707 (2014).

12. T. Echigo, M. Kimata, Crystal chemistry and genesis of organic minerals: A review of oxalate and polycyclic aromatic hydrocarbon minerals. Can. Mineral. 48, 1329-1357 (2010).

13. H. C. W. Skinner, Biominerals. Mineral Mag. 69, 621-641 (2005).

14. P. Adamo, P. Violante, Weathering of rocks and neogenesis of minerals associated with lichen activity. Appl. Clay Sci. 16, 229-256 (2000). 
15. R. L. Frost, M. Adebajo, M. L. Weier, A Raman spectroscopic study of thermally treated glushinskite-The natural magnesium oxalate dihydrate. Spectrochim. Acta A 60 , 643-651 (2004).

16. R. M. Clarke, I. R. Williams, Moolooite, a naturally occurring hydrated copper oxalate from Western Australia. Mineral Mag. 50, 295-298 (1986).

17. D. Atencio, J. M. V. Coutinho, S. Graeser, P. A. Matioli, L. A. D. Menezes Filho, Lindbergite, a new Mn oxalate dihydrate from Boca Rica mine, Galiléia, Minas Gerais, Brazil, and other occurrences. Am. Mineral. 89, 1087-1091 (2004).

18. T. Echigo, M. Kimata, Single-crystal x-ray diffraction and spectroscopic studies of humboldtine and lindbergite: Weak Jahn-Teller effect of $\mathrm{Fe}^{2+}$ ion. Phys. Chem. Miner. 35, 467-475 (2008).

19. M. Dan, C. N. R. Rao, A building-up process in open-framework metal carboxylates that involves a progressive increase in dimensionality. Angew. Chem., Int. Ed. Engl. 45 281-285 (2005).

20. R. Vaidhyanathan, S. Natarajan, A. K. Cheetham, C. N. R. Rao, New open-framework zinc oxalates synthesized in the presence of structure-directing organic amines. Chem. Mater. 11, 3636-3642 (1999).

21. H. Ōkawa, A. Shigematsu, M. Sadakiyo, T. Miyagawa, K. Yoneda, M. Ohba, H. Kitagawa, Oxalate-bridged bimetallic complexes $\left\{\mathrm{NH}(\text { prol })_{3}\right\}\left[\mathrm{MCr}(\mathrm{ox})_{3}\right]\left(\mathrm{M}=\mathrm{MnI}^{\mathrm{II}}, \mathrm{Fe}^{\prime \prime}, \mathrm{Co}^{\prime \prime} ; \mathrm{NH}(\mathrm{prol})_{3}{ }^{+}=\right.$ tri(3-hydroxypropyl)ammonium) exhibiting coexistent ferromagnetism and proton conduction. J. Am. Chem. Soc. 131, 13516-13522 (2009).

22. H. Riesen, A. D. Rae, Revisiting the crystal structure and thermal properties of NaMgAl(oxalate) $)_{3} \cdot 9 \mathrm{H}_{2} \mathrm{O} / \mathrm{Cr}(\mathrm{III})$ : An extraordinary spectral hole-burning material. Dalton Trans. 2008, 4717-4722 (2008).

23. T. S. Piper, R. L. Carlin, Polarized visible spectra of crystalline trisoxalatometallates. J. Chem. Phys. 35, 1809-1815 (1961).

24. S. Miyatsu, M. Kofu, A. Nagoe, T. Yamada, M. Sadakiyo, T. Yamada, H. Kitagawa, M. Tyagi, V. García Sakai, O. Yamamuro, Proton dynamics of two-dimensional oxalate-bridged coordination polymers. Phys. Chem. Chem. Phys. 16, 17295-17304 (2014).

25. L. J. Wang, H. Deng, H. Furukawa, F. Gándara, K. E. Cordova, D. Peri, O. M. Yaghi, Synthesis and characterization of metal-organic framework-74 containing 2, 4, 6, 8, and 10 different metals. Inorg. Chem. 53, 5881-5883 (2014).

26. S. L. James, C. J. Adams, C. Bolm, D. Braga, P. Collier, T. Friščić, F. Grepioni, K. D. M. Harris, G. Hyett, W. Jones, A. Krebs, J. Mack, L. Maini, A. G. Orpen, I. P. Parkin, W. C. Shearouse, J. W. Steed, D. C. Waddell, Mechanochemistry: Opportunities for new and cleaner synthesis. Chem. Soc. Rev. 41, 413-447 (2012).

27. C. J. Adams, M. F. Haddow, M. Lusi, A. G. Orpen, Crystal engineering of lattice metrics of perhalometallate salts and MOFs. Proc. Natl. Acad. Sci. U.S.A. 107, 16033-16038 (2010).

28. M. Lusi, J. L. Atwood, L. R. MacGillivray, L. J. Barbour, Isostructural coordination polymers: Epitaxis vs. solid solution. CrystEngComm 13, 4311-4313 (2011).

29. F. Liebau, Ordered microporous and mesoporous materials with inorganic hosts: Definitions of terms, formula notation, and systematic classification. Microporous Mesoporous Mater. 58, 15-72 (2003).
30. F. D. L. Walker, M. R. Lee, I. Parsons, Micropores and micropermeable texture in alkali feldspars: Geochemical and geophysical implications. Mineral Mag. 59, 505-534 (1995).

31. C. Volkringer, T. Loiseau, N. Guillou, G. Férey, D. Popov, M. Burghammer, C. Riekel, Synthesis and structural characterization of metal-organic frameworks with the mellitate linker $\mathrm{M}_{2}(\mathrm{OH})_{2}\left[\mathrm{C}_{12} \mathrm{O}_{12} \mathrm{H}_{2}\right] \cdot 2 \mathrm{H}_{2} \mathrm{O}(\mathrm{M}=\mathrm{Al}, \mathrm{Ga}$, In) MIL-116. Solid State Sci. 26, 38-44 (2013).

32. J. An, O. K. Farha, J. T. Hupp, E. Pohl, J. I. Yeh, N. L. Rosi, Metal-adeninate vertices for the construction of an exceptionally porous metal-organic framework. Nat. Commun. 3, 604 (2012).

33. A. C. McKinlay, R. E. Morris, P. Horcajada, G. Férey, R. Grey, P. Couvreur, C. Serre, BioMOFs: Metal-organic frameworks for biological and medical applications. Angew. Chem., Int. Ed. 49, 6260-6266 (2010).

34. I. Imaz, M. Rubio-Martínez, J. An, I. Solé-Font, N. L. Rosi, D. Maspoch, Metal-biomolecule frameworks (MBioFs). Chem. Commun. 47, 7287-7302 (2011).

35. G. M. Sheldrick, A short history of SHELX. Acta Cryst. 64, 112-122 (2008).

36. L. J. Farrugia, WinGX suite for small-molecule single-crystal crystallography. J. Appl. Cryst. 32, 837-838 (1999).

Acknowledgments: We acknowledge D. Scott Bohle (McGill University), I. Brekalo, and K. Travis Holman (Georgetown University) for their help in single-crystal XRD analysis on synthetic samples. We also acknowledge G. Díaz de Delgado (University of the Andes) and T. Blanton (International Centre for Diffraction Data) for their assistance with acquiring information on the mineral samples. Funding: I.H. and T.F. acknowledge the Natural Sciences and Engineering Research Council of Canada Discovery Grant and Fonds de recherche du Québec Nature et technologies (FRQNT) Nouveaux Chercheurs Grant for financial support. S.V.K. thanks Saint Petersburg State University (SPbSU) for financial support (internal grant 3.38.243.2015) and access to SPbSU XRD resource center. Author contributions: Experimental work on synthetic material was conducted by I.H.; experiments on natural materials were conducted by S.V.K. (single-crystal diffraction analysis) and I.V.P. (PXRD measurements). Database, literature, and mineral supplier searches were conducted by T.F. Manuscript and the Supplementary Materials were written and prepared by all authors. Competing interests: The authors declare that they have no competing interests. Data and materials availability: All data needed to evaluate the conclusions in the paper are present in the paper and/or the Supplementary Materials. Additional data are available from authors upon request. Crystallographic data for all herein discussed structures have been deposited in the Cambridge Structure Database, with deposition codes 1408093 to 1408095 for synthetic samples and 1431678 and 1431679 for natural samples. These data are available free of charge at www.ccdc.cam.ac.uk.

Submitted 23 March 2016

Accepted 7 July 2016

Published 5 August 2016

10.1126/sciadv. 1600621

Citation: I. Huskić, I. V. Pekov, S. V. Krivovichev, T. Friščić, Minerals with metal-organic framework structures. Sci. Adv. 2, e1600621 (2016). 


\section{ScienceAdvances}

\section{Minerals with metal-organic framework structures}

Igor Huskic, Igor V. Pekov, Sergey V. Krivovichev and Tomislav Friscic

Sci Adv 2 (8), e1600621

DOI: $10.1126 /$ sciadv. 1600621

ARTICLE TOOLS

SUPPLEMENTARY

MATERIALS

REFERENCES

PERMISSIONS http://advances.sciencemag.org/content/2/8/e1600621

http://advances.sciencemag.org/content/suppl/2016/08/01/2.8.e1600621.DC1

This article cites 36 articles, 7 of which you can access for free http://advances.sciencemag.org/content/2/8/e1600621\#BIBL

http://www.sciencemag.org/help/reprints-and-permissions 